\title{
Renal impairment associated with an acute paracetamol overdose in the absence of hepatotoxicity
}

\author{
Norman R.C. Campbell and Barry Baylis
}

Department of Medicine, Faculty of Medicine, The University of Calgary, Calgary, Alberta, Canada

\begin{abstract}
Summary: This report describes a paracetamol overdose in which renal impairment occurred without biochemical evidence of hepatotoxicity. We are aware of only one similar case. However, it is possible this scenario may be seen more frequently with close biochemical follow-up.
\end{abstract}

\section{Introduction}

Significant hepatotoxicity in the absence of renal impairment is common in paracetamol poisoning. ${ }^{1}$ Acute renal failure occurs following approximately $1 \%$ of overdoses involving paracetamol. ${ }^{1,2}$ In these cases, the patients generally have hepatic failure or substantial biochemical evidence of hepatic damage. $^{1-5}$ To our knowledge there is only one report of a case with acute renal impairment due to paracetamol ingestion occurring in the absence of hepatotoxicity. ${ }^{6}$ We report an additional case of an intentional paracetamol overdose, in which over $500 \mathrm{mg}$ paracetamol $/ \mathrm{kg}$ was claimed to have been ingested. The patient had no biochemical evidence of hepatotoxicity, but acute renal impairment occurred.

\section{Case report}

The patient is a 15 year old Vietnamese female who ingested 50-60 $325 \mathrm{mg}$ paracetamol tablets with no other medication or alcohol, following a dispute with her family. She presented 15 hours following the ingestion of the tablets with complaints of dizziness, mild abdominal pain and nausea, but no vomiting. She had previously been well, on no medication, and denied consumption of illicit drugs. There was no personal or family history of renal or psychiatric illness.

Correspondence: N. Campbell, M.D., F.R.C.P. (C), Department of Medicine, Faculty of Medicine, The University of Calgary, 3330 Hospital Drive NW, Calgary, Alberta, Canada, T2N 4N1.

Accepted: 9 September 1991
On presentation, she was in no distress - pulse $84 / \mathrm{min}$, blood pressure $110 / 84 \mathrm{mmHg}$, temperature $37.3^{\circ} \mathrm{C}$ and weight $38.5 \mathrm{~kg}$. The rest of the examination was within normal limits apart from mild right upper abdominal tenderness and some right flank tenderness. She was treated with $\mathrm{N}$-acetylcysteine $6 \mathrm{~g}$ intravenously over 15 minutes, followed by $2 \mathrm{~g}$ intravenously over 4 hours and a subsequen intravenous infusion of $\mathrm{N}$-acetylcysteine of 4 over 16 hours. Her paracetamol level was $181 \mu \mathrm{mol} / 1(27.3 \mathrm{mg} / \mathrm{l})$ on presentation, and was less than $33 \mu \mathrm{mol} / 1(5.0 \mathrm{mg} / \mathrm{l})$ following the $\mathrm{N}$ acetylcysteine infusion. Initial laboratory investigations revealed the following: sodium $141 \mathrm{mmol} / \mathrm{l}$, potassium $3.3 \mathrm{mmol} / \mathrm{l}$, carbon dioxide $23 \mathrm{mmol} / 1$, chloride $108 \mathrm{mmol} / \mathrm{l}$, creatinine $68 \mu \mathrm{mol} / 1$, urea $4.6 \mathrm{mmol} / 1$, glucose $7.5 \mathrm{mmol} / 1$, total protein $73 \mathrm{~g} / 1$, albumin $38 \mathrm{~g} / 1$, calcium $2.25 \mathrm{mmol} / 1$, inorganic phosphate $1.14 \mathrm{mmol} / 1$, cholesterol $4.36 \mathrm{mmol} / 1$, urate $362 \mu \mathrm{mol} / 1$, total bilirubin $9 \mu \mathrm{mol} / 1$, alkaline phosphatase $96 \mathrm{U} / 1$, creatine kinase $55 \mathrm{U} / 1$, lactate dehydrogenase $116 \mathrm{U} / 1$, aspartate transaminase $10 \mathrm{U} / 1$, prothrombin time $13 \mathrm{~s}$ (control $12.5 \mathrm{~s}$, INR 1.11 ), white blood cell count $5 \times 10^{9} / 1$, haemoglobin $134 \mathrm{~g} / \mathrm{l}$, haematocrit 0.382 , platelet count $316 \times 10^{9} / 1$. The initial urinalysis was performed on day two of the admission and was normal apart from $2+$ proteinuria.

The patient continued to have mild abdominal pain and nausea without emesis for the first 4-5 days following admission but ingested food and fluids freely. The only medication she received apart from intravenous $\mathrm{N}$-acetylcysteine (with 1.41 fluid) was a single intramuscular dimenhydrinate injection on the day of admission. There was no clinical evidence of dehydration or reduction in intravascular volume during the admission. The patient was followed closely with daily assessment 
of serum electrolytes, creatinine, biochemistry and prothrombin time, due to the quantity of paracetamol claimed to have been ingested $(>500 \mathrm{mg} / \mathrm{kg})$. The results of the serum alkaline phosphatase, aspartate transaminase, urea and creatinine can be seen in Figure 1. The serum creatinine started to rise on the third day of admission, peaking on the fourth day. At this time, urinary and serum electrolytes and creatinine were performed, which revealed a fractional excretion of sodium of $0.4 \%$ with a urine sodium of $15 \mathrm{mmol} / \mathrm{l}$. The fractional excretion of potassium was $11.4 \%$ with a plasma potassium of $3.3 \mathrm{mmol} / \mathrm{l}$. Her calculated creatinine clearance, based on the Cockcroft-Gault formula ${ }^{7}$ and corrected for body surface area, decreased from $98.6 \mathrm{ml} / \mathrm{min}$ on the day of admission to $39.2 \mathrm{ml} / \mathrm{min}$ on day 4 of the admission. There was no evidence of a reduction of intravascular volume or renal hypoperfusion from admission to the 4th hospital day based on changes in the urea to creatinine ratio $(0.068$ vs 0.065 (plasma urea mmol/l: plasma creatinine $\mu \mathrm{mol} / \mathrm{l})$ ), serum albumin $(38 v s 34 \mathrm{~g} / \mathrm{l})$ or haematocrit $(0.382$ vs 0.339). A urinalysis performed on day 4 was reported to be normal apart from $1+$ proteinuria and 5-10 epithelial cells/high power field. An ultrasound of the kidneys was performed on day 5 , which revealed increased echogenicity of the cortical region of the kidney, but was otherwise normal. Following day 4 the creatinine decreased but did not return to the initial level (Figure 1). The results of other biochemical measurements and prothrombin time measurements revealed no significant changes apart from an increase in inorganic phosphate peaking on day $4(1.8 \mathrm{mmol} / \mathrm{l})$.

\section{Discussion}

Renal dysfunction in paracetamol overdose has been well described in both humans and in animal models. ${ }^{2,4,7}$ The renal impairment is due to acute tubular necrosis clinically and histologically. ${ }^{2,4,5,7}$ The renal dysfunction in this case is consistent with paracetamol toxicity. ${ }^{1,4,5,6}$ Other causal factors appear to be less likely although they cannot be excluded without a renal biopsy. There was no clinical evidence of hypovolaemia except the low fractional excretion of sodium to suggest significant pre-renal impairment. Based on the changes in urea to creatinine ratio, serum albumin and haematocrit there was a slight increase in circulating blood volume. Furthermore, the patient had no predisposition to dehydration. While the presence of proteinuria raises the possibility of pre-existing renal disease, her admission serum creatinines and estimated creatinine clearances were normal. Further, the initial proteinuric sample was obtained almost 36 hours after the overdose

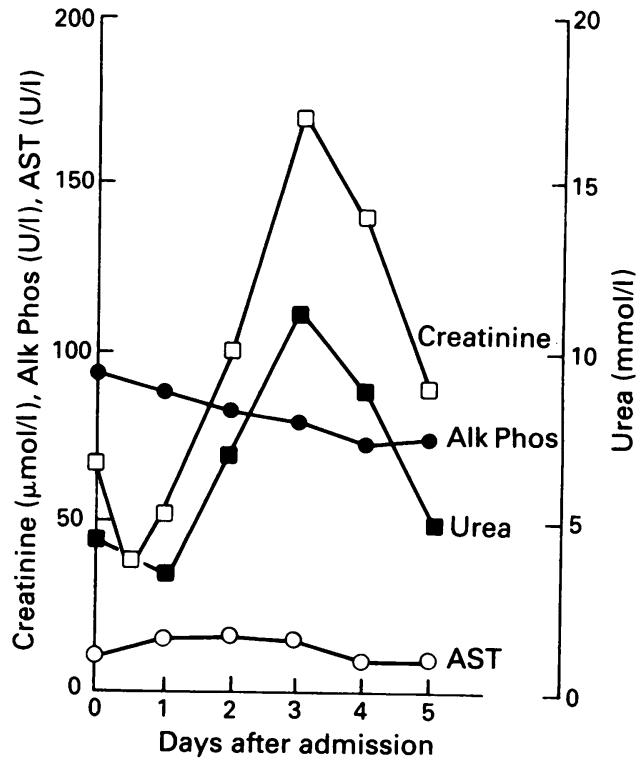

Figure 1 The changes in creatinine $(\mu \mathrm{mol} / \mathrm{l})$, urea (mmol/l) and in 'liver' enzymes aspartate aminotransferase (AST, U/l), and alkaline phosphatase (Alk Phos, $\mathrm{U} / \mathrm{l}$ ) over a period of 5 days following an admission for a paracetamol overdose in a 15 year old female.

and could represent paracetamol nephrotoxicity. In other reports of paracetamol-induced renal failure, proteinuria and hypokalaemia have been noted..$^{3-5}$ These findings may be early indicators of paracetamol nephrotoxicity.

The reason this patient developed nephrotoxicity without hepatotoxicity is not clear. The nephrotoxicity of paracetamol, similar to the hepatotoxicity, is felt to be due to the formation of toxic metabolites following metabolism of paracetamol by the P-450 enzyme system. ${ }^{8}$ In this case, a subclinical degree of renal hypoperfusion is possible in view of the reduced fractional excretion of sodium. This could have increased the nephrotoxicity of paracetamol through increased tubular re-absorption of paracetamol and its metabolites. In addition, the liver has higher activities of the enzymes glutathione transferase ${ }^{9}$ and phenol sulphotransferase. ${ }^{10,11}$ compared to the kidney. These enzymes prevent the formation of or 'detoxify' the reactive paracetamol metabolites. ${ }^{12}$ Moreover, glutathione transferase ${ }^{9}$ and phenol sulphotransferases $^{10,11}$ require the co-substrates glutathione and sulphate which are depleted in overdoses of paracetamol. Administration of $\mathrm{N}$-acetylcysteine repletes the sulphate ${ }^{12}$ and glutathione levels ${ }^{13}$ thereby increasing the detoxification of paracetamol. $\mathrm{N}$-acetylcysteine may be more effective at reducing hepatotoxicity. ${ }^{6}$ The loss of more than 
$60 \%$ of renal function in this case was non-oliguric and asymptomatic, and without close biochemical follow-up would not have been observed. Nephrotoxicity may occur more frequently with paracetamol overdoses than is currently reported.

\section{References}

1. Hamlyn, A.N., Douglas, A.P. \& James, O. The spectrum of paracetamol (acetaminophen) overdose: clinical and epidemiological studies. Postgrad Med J 1978, 54: 400-404.

2. Cobden, I., Record, C.O., Ward, N.K. \& Kerr, N.D.S. Paracetamol-induced renal failure in the absence of fulminant liver damage. $\mathrm{Br}$ Med J 1982, 284: 21-22.

3. Jeffrey, W.H. \& Lafferty, W.E. Acute renal failure after acetaminophen overdose: report of two cases. Am J Hosp Pharm 1981, 38: 1355-1358.

4. Curry, R.W., Robinson, J.D. \& Sughrue, M.J. Acute renal failure after acetaminophen ingestion. JAMA 1982, 247: 1012-1014.

5. Kleinman, J.G., Breitenfield, R.V. \& Roth, D.A. Acute renal failure associated with acetaminophen ingestion: report of a case and review of the literature. Clin Nephrol 1980, 14: 201-205.

6. Kher, K. \& Makker, S. Acute renal failure due to acetaminophen ingestion without concurrent hepatotoxicity (letter). Am J Med 1987, 82: 1280-1281.

7. Cockroft, D.W. \& Gault, M.H. Prediction of creatinine clearance from serum creatinine. Nephron 1976, 16: 31-41.

\section{Acknowledgements}

We would like to acknowledge the Division of Family Practice, University of Calgary for their excellent inpatient care and Heather Arcari for her expert secretarial assistance.

8. McMurtry, R.J., Snodgrass, W.R. \& Mitchell, J.R. Renal necrosis, glutathione depletion, and covalent binding after acetaminophen. Toxicol Appl Pharmacol 1978, 46: 87-100.

8. Pacifici, G.M., Franchi, M., Colizzi, C., Giuliani, L. \& Rane, A. Glutathione S-transferase in humans: development and tissue distribution. Arch Toxicol 1988, 61: 265-269.

9. Campbell, N.R.C., Van Loon, J. \& Weinshilboum, R.M. Human liver phenol sulfotransferase: assay conditions, biochemical properties and partial purification of isozymes of the thermostable form. Biochem Pharmacol 1987, 36: $1435-1446$.

10. Anderson, R.J. \& Weinshilboum, R.M. Phenolsulfotransferase in human tissues: radiochemical enzymatic assay and biochemical properties. Clin Chim Acta 1980, 103: 79-90.

11. Levy, G., Galinsky, R.E. \& Huei Lin, J. Pharmacokinetic consequences and toxicologic implications of endogenous cosubstrate depletion. Drug Met Rev 1982, 13: 1009-1020.

12. Deveny, I.P. \& Saunder, S.J. Physicians handbook for medical management for alcohol and drug related problems. Ontario Medical Association, Toronto, Ontario, 1986. 